\title{
Elementary Learners' Life in a Synchronous Learning during the Pandemic
}

\author{
Fabiana P. Peñeda, MAT ${ }^{\mathrm{a}}$, Thea A. Ticoy, MAPre-Ed ${ }^{\mathrm{b}}$ \\ a fabiana.peneda@lnu.edu.ph \\ ${ }^{a}$ Leyte Normal University, Paterno Street, Tacloban City, 6500, Philippines \\ b Leyte Normal University, Paterno Street, Ta cloban City, 6500, Philippines
}

\begin{abstract}
During the Covid-19 outbreak, synchronous learning has become one of the new learning modalities in the Philippines. The study used a single case study that focused on the participants' difficulties and coping mechanisms relative to synchronous learning. Ten (10) Grade 6 pupils of a laboratory school in Tacloban City were purposely selected as participants of the study. The study data were collected using an interview guide and focus group discussion through google meet, and data were analyzed using Wa-Mbaleka (2018) method. The study is guided by the flexible learning theory of Gearhart (2008) and E-learning theory (David, 2015). Findings showed that difficulties of synchronous learning include: technological dilemmas, unfulfilled house commitments, lack of digital materials, and absence of selfmanagement. Furthermore, coping mechanisms include resilient social support and upholding educational accountability. Findings will be used to understand learners' perceptions regarding online learning and enhance online strategies and materials.
\end{abstract}

Keywords: synchronous learning; flexible learning theory; elementary learners; case study

\section{Introduction}

Recently, the Coronavirus outbreak hit the education system in all countries, which put many educational institutions on high alert (Onyema, E.M. et al., 2020). This pandemic resulted in many unfortunate consequences, particularly in the Philippines' educational system. The Philippines is a third -world country where there is a high possibility of negatively impacting education. This impact is observable to those Filipino children already having difficulties in learning before the pandemic, how much more now that the Philippine education system is unprepared for the high incidence of the pandemic.

Learning environment such as schools matters a lot to the learners, particularly at the elementary levels. This place is where students' learning occurs. Learning is necessary to understand what he is reading and analyze mathematical problems independently. These are only a few reasons why schools are essential. 
Through learning, learners can proceed to another level and get their graduate diploma. Once education stop, it paralyzes the dream and ambition of a learner. It is one of the responsibilities of parents, teachers, and school administrators to think of an alternative for students to continue learning during a catastrophe.

Hence, Fay et al. (2020) emphasized that schools allow learners to have physical a nd cognitive development alongside the learning partners in education. Thus, many learners nowadays are not going to school, but some tend to attend synchronous learning modality, particularly the elementary learners. Nevertheless, unfortunately, no research study has been conducted at a particular integrated school to determine the difficulties they encountered and how they dealt with them in asynchronous learning during the COVID 19 pandemic in Tacloban City.

Academes participate in all learners' learning success, particularly synchronous learning at the elementary level. Neglecting this responsibility today in education during pandemics leads to stagnant learning and lessens learners' motivation to go back to school. The particular situation leads to poor comprehension and high illiteracy if not given attention by those authorities in education. Therefore, the researcher would like to identify the difficulties encountered by the elementary learners during synchronous learning and how they deal with those difficulties.

\section{Theoretical Framework}

The study was supported by Gearhart's Flexible learning theory and David's E-learning theory.

Flexible learning theory, as defined by Gearhart (2008), is a method for engaging the various learning needs of children during a given phenomenon. Despite the current circumstances, James et al. (2001) emphasizes that one of the characteristics of flexible learning is technology, which provides understanding and encourages collaboration and interaction between teacher and learners. The relevance of the theory explains how elementary learners' experiences during synchronous learning have changed over time. When dealing with their challenges in synchronous learning, elementary learners can be more patient and resourceful. Despite the lack of digital devices and a slow internet connection, they maintain self-control and creative thinking. Elementary learners develop personal responsibility during the pandemic and have a sturdy learning support system; thus, synchronous learning difficulties are not a barrier.

David (2015) explained E-learning theory, stating that there is evidence of learning through educational technology, which can improve the cognitive level of the learners. In addition, Kerimbayev et al. (2020) agreed that E-learning plays an essential role in education by utilizing electronic tools observable in synchronous learning. Wu et al. (2010) agree that E-learning theory demonstrates how synchronous learning can help deliver learning opportunities and foster a positive virtual learning environment. This theory enables this study to tailor learning through synchronous modality, which aids elementary students in gaining more 
knowledge. It also exemplifies how elementary students can interact with their teachers and classmates and acquire knowledge while enjoying learning from asynchronous modality.

\section{Review of Literature}

The education sectors made sudden changes as they shifted to emergency remote education (Bozkurt et al., 2020). In response to the current state brought by the Covid-19, school administrators to adopt the new normal in education, particularly synchronous learning. Synchronous education is a process where teachers and learners do their classes using the online learning modality. However, this online modality of learning tends to encounter many difficulties, particularly on the side of the learners. Anthony \& Clark (2011) emphasized that learners' difficulties in technology affect students' academic motivation.

Also, Ozkara \& Cakir (2018) said that it hurts learners' inspiration and learning the technical challenges encountered in synchronous education. In addition, Niemi \& Kousa (2020) explained that the situation is alarming because learners were not technologically prepared to adopt synchronous education. UNESCO (2020) explained further that those learners attend synchronous education even with limited learning resources, which leads them to experience difficulties in attending the online class. Hall et al. (2020) said learners tend to worry because they do not know how to use the gadgets used in online learning during the pandemic. Rahiem (2020) proved that technological difficulties hinder learning, particularly the lack of ICT skills, devices, and inadequate learning platforms.

Elementary learners asked their parents for assistance in submitting requirements and attending synchronous classes given the schedule. Even in times of a pandemic, assistance from members of society will find studying enjoyable. Assistance such as supplying the students with devices improves their confidence to fulfill and submit their time requirements. By assuming one's responsibility, the cu rrent situation also improves its efficiency. While no support comes from the environment, they will make them responsible learners as long as they recognize their school responsibility, such as completing their school assignments, attending synchronous classes, and submitting school requirements. At this point, responsible learners are essential to achieving the lesson's objectives in synchronous modality.

It allows synchronous education to be more stimulating and inspiring by offering interactive and project-based learning support. Education is evident in the teacher's strategies of 'understanding' what is advantageous in a class of 'constructive education' as students exercise self-technology over their ideas and behaviors (Hassett, 2006). The situation involves all educators, especially teachers, understanding and extending help to those who cannot meet the requirements.

\section{Research Questions}

This research study identifies the perspectives of the elementary learners in terms of their difficulties and 
how they deal with the experiences in synchronous education. This study would help elementary learners be more engaged in synchronous education, and teachers can give interventions on the difficulties they encounter. Therefore, the following questions were sought after:

1. What are the difficulties of the elementary learners exposed to synchronous learning?

2. How do elementary learners deal with the difficulties encountered in synchronous learning?

\section{Methodology}

\subsection{Research Design}

The purpose of this study was to examine the difficulties and coping mechanisms faced by elementary students enrolled in synchronous learning using a descriptive single case study method.

\subsection{Research Locale}

The researcher researched one of the schools in Tacloban City, Leyte. In the laboratory school, students receive a foundational education from Kindergarten to Grade 11. This school produces students who are academically successful as well as effective community leaders.

\subsection{Research participants \& Sampling}

For the School Year 2020-2021, ten sixth-graders were purposefully selected from a laboratory school part of the basic education program and are officially enrolled for that school year. Participants selected are from the same class, grade, and age level, and they have had similar experiences with synchronous learning.

\subsection{Research instrument, Data collection and procedure}

The survey questionnaire was administered through a Google Form, which experts validated before being used in the study. The survey questionnaire included questions about the difficulties they were experiencing and how they were dealing with synchronous schooling. Each participant's parent was asked to agree to their child's participation in the research study before the study began. As part of that process, participants participated in recorded virtual focus group discussions about their perspectives on synchronous education among elementary school learners. The questionnaire is the most appropriate process because it allows researchers to collect information from a wide range of participants. The findings are being kept private. The transcribed data was returned to the participant to verify the validity of the results based on their responses to the google form and interview. The participants' perceptions served as the basis for the analysis of each theme in the study.

\section{5 Ethical Considerations}

Participants' names were not revealed, and all recorded information and photographs were appropriately archived to maintain their privacy. Despite being elementary teachers, researchers used a 
systematic approach to gather data to avoid biased information about the difficulties faced by elementary learners exposed to synchronous learning and how they deal with those difficulties in synchronous learning.

5.6 Data Analysis

The data gathered in the study were analyzed using the methods described by Wa-Mbaleka (2018), which included the following steps: 1) prepare and organize your date, 2) ready your transcripts once or twice, 3) develop your coding manual, 4) code all your data, 5) find recurring ideas, 6) abstract your ideas, 7) write the interpretation of all your data, 8) write your report, 9) verify your findings a nd conclude, and 10) make final revisions.

\section{Results and Discussion}

The themes centered on the participants' difficulties and their strategies for overcoming the difficulties associated with synchronous learning.

\section{Elementary learners' difficulties encountered in synchronous education}

\section{Theme 1: Technological dilemmas}

Synchronous education can be affected by the technical problems encountered by students. Having difficulty connecting to the gadget will reduce students' willingness to learn, especially during synchronous learning (Hussein et al., 2020). In synchronous education, the technological dilemmas of learners can have an impact on the learning performance of learners. To not affect the learners' performance, educators must be conscious of this scenario.

Significant Response 1: "Technical issue when answering that LMS or the modules given becomes disoriented, difficulty on editing answers on Microsoft, sometimes difficulty on understanding the lesson."

Significant Response 2: "Ha ving Unstable Internet Connection and No Internet Connection."

Significant Response 3: "Lost connection, lost signal, sometimes if the student teacher lost connection ma'am extended time, expensive internet, online platform being used requires a large a mount of data."

Significant Response 4: "Laptop lagging, slow wifi, camera and mic struggle, brownout while we are having classes, signal is slow, the headphones I can't hear."

\section{Theme 2: Unfulfilled house commitments}

During a pandemic, children learn predominantly at home. The majority of them help each other with household chores. However, it impacts students' synchronous learning because their attention is divided 
between attending the synchronous session and fulfilling household responsibilities. Gillis and Krull (2020) agree that household obligations can cause pupils to have difficulty attending synchronous learning sessions, causing them to be unable to concentrate on the activities assigned by the teacher.

Significant Response 1: "I experience unstable internet, I sometimes have to help my family

because we are few in the house at the moment and I tend to get distracted by things sometimes."

\section{Theme 3: Lack of digital materials}

Digital materials are needed to attend the synchronous session because it can make it hard for people to stay in the online class. A study conducted by Kim (2020) found that digital materials are beneficial for learners participating in synchronous learning because they allow them to connect and keep track of their lessons. However, the absence of digital materials has been shown to negatively impact a learner's learning and performance (Ferri et al., 2020). Thus, synchronous learning absenteeism can affect how well the lesson is learned. People can also ask their teacher for more information during the synchronous session instead of learning about the same thing at their own pace.

Significant Response 1: "Poor connection, lack of gadgets to use for E-learning, lacking school attendance due to poor connection, lacking school activities, answering school activities with poor connection."

Significant Response 2: "laptop lagging, slow wifi, camera and mic struggle, brownout while we are having classes, signal is slow, the headphones I can't hear."

\section{Theme 4: Absence of Self-control}

Learning through synchronous means can demonstrate a learner's ability to take responsibility. The inability to maintain self-control will impair the attentiveness of those participating in the synchronous session because they will not comprehend the lesson (Goldberg et al., 2020). Learners are unable to comprehend and participate in the teacher's discussion, resulting in a lack of motivation for them. Learners who cannot maintain their self-control will fail to fulfill their responsibilities as students. Lack of self-control will prevent students from achieving educational success, mainly when teachers are not physically present to correct poor study habits in their own home.

Significant Response 1: "I experience unstable internet, I sometimes have to help my family because we are few in the house at the moment and I tend to get distracted by things sometimes." Significant Response 2: "The challenges I encountered were Struggling, to adapt to the new ELearning, having technical issues, Time management as there is times where you can't learn properly because of the time, lack of motivation, and lastly the lack of being social." 


\section{Elementary learners deal with the difficulties encountered in synchronous education}

\section{Theme 1: Resilient social support}

People in the immediate vicinity impact the education of elementa ry students in particular. If someone is assisting learners with their educational needs, they will succeed and do well in their studies. Family members, classmates, friends, and teachers are all people who can lend a helping hand to the educational journey of all students as academic success (Karasmanaki \& Tsantopoulos (2021). Having a strong bond among society members made it so much more achievable and straightforward for elementary students to learn in difficult times, particularly in synchronous learning, one of the Philippines' new learning trends, particularly in difficult moments.

Significant Response 1: "On technical issue I am consulting my subject teachers, on difficulty on editing the Microsoft, I am asking assistance from my parents, also if I am not able to understand well my lessons, I am asking help from my parents to have me more explanation about the lesson."

Significant Response 2: "I asked my mother if I can get mobile date so I can be sure I won't disconnect from class, I just help fast but surely and for the last one I just remove the distractions."

Significant Response 3: "I will try to borrow my siblings' gadgets if they are not using it."

Significant Response 4: "I will ask my classmates or if they had a poor connection or didn't att end class I will just go to the LMS and try to find the lesson."

\section{Theme 2: Upholding educational accountability}

Synchronous learning assesses all learners' ability to deal with the current learning situation. No teachers or family members can frequently assist them in their synchronous schooling at home, so they must be aware of their responsibilities. According to Kemmer (2011), responsible students understand some of the expectations in their educational journey, such as completing missing school work, attending the synchronous session, asking classmates questions during an absence in an online class, and putting in an extra effort to learn the lesson well individually. Starting in grade school with the right attitude will ensure progress and achievement in their lives.

Significant Response 1: "What I did is that I will just go to the LMS for the discussion video as it was instructed by our teacher."

Significant Response 2: "If I missed a meeting, I will ask my classmates what was the lesson they discussed."

Significant Response 3: "I find a way to manage that problem."

Significant Response 4: "And from overcoming these challenges I stayed positive, faced the challenges head on, didn't complain, and stayed realistic." 


\section{Conclusion}

Elementary learners' viewpoints on the difficulties they have encountered and how they have dealt with them during synchronous learning help them recognize the importance of multimedia and self-learning responsibilities. These could aid in the preparation of valuable lessons in synchronous learning for teachers and administrators and the provision of necessary resources. Effective online strategies for elementary learners and independent learning are demonstrated as assets of ineffective elementary education. A new setting in the school system that has emerged in the current situation recognizes elementary learners' development as they participate in synchronous learning.

\section{References}

Anthony, A. B., \& Clark, L. M. (2011). Examining dilemmas of practice associated with the integration of technology into mathematics classrooms serving urban students. Urban Education, 46(6), 1300-1331.

Bandura, A., \& McClelland, D. C. (1977). Social learning theory (Vol. 1). Prentice Hall: Englewood cliffs.

Ferri, F., Grifoni, P., \& Guzzo, T. (2020). Online learning and emergency remote teaching: Opportunities and challenges in emergency situations. Societies, $10(4), 86$.

Gillis, A., \& Krull, L. M. (2020). <? covid19?> COVID-19 Remote Learning Transition in Spring 2020: Class Structures, Student Perceptions, and Inequality in College Courses. Tea ching Sociology, 48(4), 283-299.

Goldberg, P., Sümer, Ö., Stürmer, K., Wagner, W., Göllner, R., Gerjets, P., ... \& Trautwein, U. (2021). Attentive or not? Toward a machine learning approach to as sessing students' visible engagement in classroom instruction. Educational Psychology Review, 33(1), 27-49.

Hassett, D. D. (2006). Technological difficulties: a theoretical frame for understanding the non-relativistic permanence of traditional print literacy in elementary education. Journal of Curriculum Studies, 38(2), 135-159.

Hussein, E., Daoud, S., Alrabaiah, H., \& Badawi, R. (2020). Exploring undergraduate students' attitudes towards emergency online learning during COVID-19: A case from the UAE. Children and Youth Services Review, 119, 105699.

Karasmanaki, E., \& Tsantopoulos, G. (2021). Impacts of social distancing during COVID-19 pandemic on the daily life of forestry students. Children and youth services review, 120,105781.

Kemmer, D. (2011). Blended learning and the development of student responsibility for learning: a case study of a 'widening a ccess' university. Widening Participation and Lifelong Learning, 13(3), 60-73.

Kerimbayev, N., Nurym, N., Akramova, A., \& Abdykarimova, S. (2020). Virtual educational environment: interactive communication using LMS Moodle. Education and Information Technologies, 25(3), 1965-1982.

Kim, J. (2020). Learning and teaching online during Covid-19: Experiences of student teachers in an early childhood education practicum. International Journal of Early Childhood, 52(2), 145-158.

Lefa, B. (2014). The Piaget theory of cognitive development: an educational implication.Educational psychology, 1(9), 1-8.

Niemi, H. M., \& Kousa,P. (2020). A case study of students' and teachers' perceptions in a Finnish high school during the COVID pandemic. International journal of technology in education and science.

Ozaydin Ozkara, B., \& Cakir, H. (2018). Participation in online courses from the students' perspective. Interactive Learning Environments, 26(7), 924-942.

Piaget, J. (1983). Piaget's theory. P. Mussen (ed). Handbook of Child Psychology. 4th edition. Vol. 1. New York: Wiley.

UNESCO (2020) Policy Brief: Education during COVID-19 and beyond. United Nations.

Rahiem, M. D. (2020). Technological barriers and challenges in the use of ICT during the COVID- 19 emergency remote learning. Universal Journal of Educational Research, 8(11B), 6124- 6133.

Wu, J. H., Tennyson, R. D., \& Hsia, T. L. (2010). A study of student satisfaction in a blended e-learning system environment. Computers \& Education, 55(1), 155-164. 